\title{
The performance of dental pulp stem cells on nanofibrous PCL/gelatin/nHA scaffolds
}

\author{
Xuechao Yang, ${ }^{1,2,3}$ Fang Yang, ${ }^{3}$ X. Frank Walboomers, ${ }^{3}$ Zhuan Bian, $^{1}$ Mingwen Fan, ${ }^{1}$ John $^{\text {A. Jansen }}{ }^{3}$ \\ ${ }^{1}$ Key Laboratory for Oral Biomedical Engineering of Ministry of Education, School and Hospital of Stomatology, \\ Wuhan University, 237 Luoyu Road, Wuhan 430079, Hubei Province, People's Republic of China \\ ${ }^{2}$ Department of Endodontics, School and Hospital of Stomatology, Wuhan University, 237 Luoyu Road, \\ Wuhan 430079, Hubei Province, People's Republic of China \\ ${ }^{3}$ Department of Periodontology and Biomaterials, Radboud University Nijmegen Medical Centre, \\ PO Box 9101, 6500 HB Nijmegen, The Netherlands
}

Received 12 December 2008; revised 16 March 2009; accepted 16 March 2009

Published online 25 June 2009 in Wiley InterScience (www.interscience.wiley.com). DOI: 10.1002/jbm.a.32535

\begin{abstract}
The aim of current study is to investigate the in vitro and in vivo behavior of dental pulp stem cells (DPSCs) seeded on electrospun poly( $\epsilon$-caprolactone) (PCL)/gelatin scaffolds with or without the addition of nano-hydroxyapatite (nHA). For the in vitro evaluation, DNA content, alkaline phosphatase (ALP) activity and osteocalcin (OC) measurement showed that the scaffolds supported DPSC adhesion, proliferation, and odontoblastic differentiation. Moreover, the presence of nHA upregulated ALP activity and promoted OC expression. Real-time PCR data confirmed these results. SEM micrographs qualitatively confirmed the proliferation and mineralization characteristics of DPSCs on both scaffolds. Subsequently, both scaffolds seeded with DPSCs were subcutaneously implanted into immunocompromised nude mice. Scaffolds
\end{abstract}

with nHA but without cells were implanted as control. Histological evaluation revealed that all implants were surrounded by a thin fibrous tissue capsule without any adverse effects. The cell/scaffold composites showed obvious in vivo hard tissue formation, but there was no sign of tissue ingrowth. Further, the combination of nHA in scaffolds did upregulate the expression of specific odontogenic genes. In conclusion, the incorporation of nHA in nanofibers indeed enhanced DPSCs differentiation towards an odontoblast-like phenotype in vitro and in vivo. (C) 2009 Wiley Periodicals, Inc. J Biomed Mater Res 93A: 247-257, 2010

Key words: dental pulp stem cells; electrospinning; nanohydroxyapatite; poly( $\varepsilon$-caprolactone); gelatin

\section{INTRODUCTION}

In dentistry, the emergence of tissue engineering techniques presents a prospect for the development of natural tooth substitutes, which may provide a better solution than irreversible repair methods, for example, the use of dental restorations or oral implants. In general, dental tissue engineering requires three basic elements: an appropriate cell source, a biodegradable scaffold to serve as a temporary extracellular matrix (ECM) and optimal sig-

Correspondence to: J. A. Jansen; e-mail: J.Jansen@dent. umcn.nl

Contract grant sponsor: Royal Netherlands Academy of Arts and Sciences (KNAW); contract grant numbers: 06CDP030, 04-PSA-M-02

Contract grant sponsor: Dutch Program for Tissue engineering; contract grant numbers: DPTE, NGT 6730

(C) 2009 Wiley Periodicals, Inc. nals for cell functioning. Regarding the cell source, dental pulp-derived adult stem cells (DPSCs) are especially attractive because they showed potential for odontogenic differentiation and the ability to form a regular-shaped dentine-pulp complex. ${ }^{1,2}$ To support cell proliferation and function in vivo, a scaffold structure is often critical to recapitulate the in vivo milieu and to allow cells to influence their own microenvironment. ${ }^{3}$ Recently, the electrospinning technique has been developed to synthesize highly porous nonwoven fabrics consisting of ultrafine fibers that mimic the architecture and mechanical properties of ECM of native tissues. ${ }^{4,5}$ Numerous studies have already shown the potential of electrospun scaffolds in bone regeneration, dermal reconstitution, cartilage repair, blood vessel and neural tissue engineering, but all aforementioned knowledge has never been involved in dental tissue engineering. ${ }^{6-11}$

The starting material in the electrospinning process can be chosen from both synthetic and natural 
polymers. For synthetic materials, however, the major disadvantage is the lack of cell recognition signals. This problem can be overcome by blending the synthetic substance with natural materials. For instance, poly( $\varepsilon$-caprolactone) (PCL), a biodegradable and biocompatible polymer often used for bone tissue engineering, has been blended with gelatin to result in a new biomaterial with biocompatibility and good mechanical, physical and chemical properties. ${ }^{8,12}$ Although showing better biocompatibility, gelatin is rarely used for tissue engineering without crosslinking treatment. However, crosslinked gelatin may not degrade and nay loose its bioactivity. In the body temperature it may not readily dissolve and gradually leach away from the scaffold with time. In contrast, mixing gelatin with other (synthetic) polymers is a feasible approach that may not only reduce the potential problem of cytotoxins resulting from chemical crosslinking reagents, but also provides a compromise solution for overcoming the shortcomings of synthetic polymers. Therefore the rationale of the current study was to producing a new biomaterial based on non-crosslinked gelatin, blended with PCL. Such a material is hypothesized to exhibit good biocompatibility and improved mechanical and physical/chemical properties.

For dental tissue engineering it might be useful to further supplement the polymer materials with hydroxyapatite (HA), as HA is the major inorganic component of teeth, and has for instance been used extensively in dental pulp capping. ${ }^{13}$ Especially nano-sized HA (nHA), mimicking the HA crystals in natural tissues, has been shown to induce a significant increase in protein absorption and cell adhesion, compared to micro-sized material. ${ }^{14,15}$ Meanwhile, nHA has a relatively high solubility compared with its micro counterpart and also contributes towards the hydrophilicity of the matrix. In general, it is required for the scaffold to possess optimal hydrophilicity for favorable cell adhesion and growth. Recent studies have already indicated that the addition of nHA in polymer scaffolds resulted in increased adhesion and growth of osteoblast-like cells. ${ }^{16-18}$ Although DPSCs have similar properties as osteoblast-like cells, their response to scaffold materials is different. ${ }^{19}$

Therefore, the main purpose behind our current study is to investigate DPSCs seeded on electrospun $\mathrm{PCL} /$ gelatin scaffolds with or without nHA. In our research strategy we will focus on quantifying the odontoblastic behavior of the cells both in vitro and in vivo by means of biochemical assays and PCR in addition to morphological observation. We hypothesize that electrospun scaffolds are adequate to support DPSCs, and furthermore that addition of nHA to a scaffold will enhance the differentiation process of adherent cells.

\section{MATERIALS AND METHODS}

\section{Nano-hydroxyapatite synthesis and characterization}

Nano-hydroxyapatite (nHA) was synthesized following a precipitation reaction. In brief, $0.3 \mathrm{M}$ orthophosphoric acid $\left(\mathrm{H}_{3} \mathrm{PO}_{4}\right)$ (Acros Organics, New Jersey, USA) was added drop wise to $0.5 M$ calcium hydroxide $\left(\mathrm{Ca}(\mathrm{OH})_{2}\right)$ (Mallinckrodt Baker, New Jersey, USA) suspension under continuous stirring overnight at room temperature, while the $\mathrm{pH}$ was kept above 10.5 by the addition of ammonia solution. Then, the obtained precipitate was aged for one week at room temperature. After centrifugal washing with deionized water, the resultant was freeze-dried to obtain very fine particles.

To observe the morphology, one drop of an aqueous dispersion of the obtained particles was put on a Formvarcoated copper grid and air dried at room temperature. The dried grid was examined using a JEOL 1101 transmission electron microscope (TEM, JEOL, Tokyo, Japan). The crystallographic structure of the particles was verified using a Philips $\theta-2 \theta$ diffractometer (XRD, PW3710, Eindhoven, The Netherlands) with $\mathrm{CuK} \alpha$-radiation $(40 \mathrm{kV}, 30 \mathrm{~mA})$. The scanning range was from 20 to $40^{\circ}$ with a step size of $0.02^{\circ}$. The chemical structure of the particles was examined using Fourier-transform infrared spectrometry (FTIR, Spectrum One, Perkin-Elmer) with an ATR accessory.

\section{Electrospinning}

The electrospinning dope without nHA was prepared from gelatin (Type A, approx. 300 Bloom, Sigma) and poly( $\varepsilon$-caprolactone) (PCL, $M_{\mathrm{n}}=80,000$, Sigma). Gelatin and PCL were dissolved in 90\% 2,2,2-trifluroethanol (TFE) (Acros Organics, New Jersey, USA) at a concentration of $12 \% \mathrm{w} / \mathrm{v}$. The weight ratio of gelatin and PCL was fixed at $1: 1$ in this study. For the electrospinning dope containing $\mathrm{nHA}$, a defined amount of nHA was suspended in the solvent by ultrasonic and vigorous stirring before adding the polymers. The polymer:nHA weight ratio was 5:1. For convenience, the electrospun PCL/gelatin scaffold is called F1, and PCL/gelatin/nHA as F2.

A commercially available electrospinning set-up (Advanced Surface Technology, Bleiswijk, The Netherlands) was used for the scaffold fabrication, as described previously. ${ }^{20}$ Briefly, $10 \mathrm{~mL}$ of the prepared dope was fed into a syringe, which was controlled by a syringe pump (KD Scientific Inc., MA, USA) at a feeding rate of $2 \mathrm{~mL} / \mathrm{h}$. A Teflon tube was used to connect the syringe and a blunt-end nozzle with an inner diameter of $0.5 \mathrm{~mm}$, which was set up vertically. The distance between the nozzle and a grounded collector was adjusted to $8 \mathrm{~cm}$. A high voltage of $20 \mathrm{kV}$ was applied to generate a polymer jet. The resulting fibers were collected on a piece of alumina foil, left in a fume hood overnight to eliminate the solvent residue and then kept in a desiccator for further experimentation.

The prepared electrospun fibrous sheets had a thickness of about $0.3 \mathrm{~mm}$, and for the various assays circular discs with a diameter of $15 \mathrm{~mm}$ were punched out of these sheets. The morphology of the three types of fabricated 
scaffolds was observed by scanning electron microscopy (SEM, JEOL 6310, Japan) and TEM. The fiber diameters were measured from SEM micrographs obtained at random locations $(n=100)$. A water wettability test was performed following a method described previously. ${ }^{20}$ In brief, a drop of $10 \mu \mathrm{L}$ deionized water was applied on the surface of the scaffolds and then photographed for contact angle calculation. All the scaffolds were tested in triplicate.

\section{Cell seeding and culture}

STRO-1 selected rat DPSCs were obtained as described previously. ${ }^{21}$ Before cell seeding, all scaffolds were sterilized and prewet in $70 \%$ ethanol for $30 \mathrm{~min}$. After being washed in phosphate buffer saline (PBS), they were incubated in $\alpha$-MEM supplemented with $10 \%$ fetal calf serum (FCS) overnight. Then, the rat DPSCs were seeded onto both types of scaffolds by incubating in a suspension of 5.0 $\times 10^{6}$ cells $/ \mathrm{mL}$ while gently rotating at $6 \mathrm{rpm}$ for $3 \mathrm{~h}$. For every 6 scaffolds, $1 \mathrm{~mL}$ cell suspension was used. Then, the cell-scaffold complexes were transferred into 24-well plates and cultured in $\alpha$-MEM supplemented with $10 \%$ FCS, $10 \mathrm{mM}$ sodium $\beta$-glycerophosphate, $10^{-8} \mathrm{M}$ dexamethasone, $\mathrm{L}$-ascorbic acid $(50 \mu \mathrm{g} / \mathrm{mL})$, and gentamycin $(50 \mu \mathrm{g} / \mathrm{mL})$. Culture medium was refreshed at 2 or 3-day intervals.

\section{Cell proliferation and alkaline phosphatase activity}

To assess the proliferation rate of the cells, total DNA content $(n=3)$ was measured by a PicoGreen dsDNA quantification kit (Molecular Probes, Leiden, The Netherlands) on day $1,4,8,16$, and 24 postseeding as described previously. ${ }^{1}$ In brief, after washing twice in PBS, each scaffold was transferred to a tube and $1 \mathrm{~mL}$ of deionized water was added to lyse the cells. Thereafter, the cellscaffold complexes together with the $1 \mathrm{~mL}$ water were subjected to a freeze-thaw cycle and sonicated for $15 \mathrm{~min}$. Then, $100 \mu \mathrm{L}$ of PicoGreen working solution was added to $100 \mu \mathrm{L}$ of supernatants of the samples. Subsequent to $2-5$ min of incubation, the DNA was measured on a fluorescence microplate reader (Bio-Tek Instruments Inc., Winooski, VT, USA), with excitation of $265 \mathrm{~nm}$ and emission of $450 \mathrm{~nm}$, and the DNA amounts were calculated from a standard curve.

The same supernatants of the samples were also used to measure alkaline phosphatase (ALP) activity $(n=3)$. Twenty $\mu \mathrm{L}$ of 0.5 AMP buffer (Sigma) was added to $80 \mu \mathrm{L}$ of the samples or standards. Next, $100 \mu \mathrm{L}$ of substrate solution was added and the mixtures were incubated at $37^{\circ} \mathrm{C}$ for $1 \mathrm{~h}$. ALP activity was measured at $405 \mathrm{~nm}$, using an ELISA microplate reader (Bio-Tek Instruments Inc., Winooski, VT, USA).

\section{Osteocalcin assay}

The deposition of osteocalcin in the extracellular matrix was used as a marker of late differentiation of DPSCs. The amount of osteocalcin was measured by an enzyme immunoassay (EIA; Biomedical Technologies, Inc.,
Stoughton, MA, USA) according to the instructions of the manufacturer. Briefly, cell/scaffold composites $(n=3)$ were treated at day 16 and 24 by $0.5 \mathrm{~mL}$ sample buffer at $4^{\circ} \mathrm{C}$ overnight after washing twice with PBS. Then, the supernatants were collected and assayed according the manufacture instruction. A rat osteocalcin standard solution was diluted to generate a standard curve $(0-40 \mathrm{ng} / \mathrm{mL})$.

\section{Scanning electron microscopy (SEM)}

On day 1, 4, and 16 after cell seeding, cell-scaffold complexes $(n=2)$ were washed in PBS twice and fixed in $2 \%$ glutaraldehyde for $15 \mathrm{~min}$. Then, the samples were dehydrated in graded series of ethanol and air-dried in tetramethylsilane (Merck, Germany). After gold sputtering, the specimens were examined with a JEOL 6310 SEM (Tokyo, Japan). As a blank control, F2 scaffolds were investigated, which were incubated in the same culture medium but without cells.

\section{Real-time quantitative PCR}

On day 4, 8, and 16 after cell seeding, total RNA of every sample (pooled from six scaffolds) was prepared with Qiagen RNEasy kit (RNeasy kit, QIAGEN, Venlo, The Netherlands). Then, $1 \mu \mathrm{g}$ of total RNA was used to perform the reverse transcriptase (RT)-reaction. The obtained cDNA was used as a template in PCR. The odontogenic differentiation of cells was monitored by specific markers, osteocalcin $(O C)$, bone sialoprotein $(B S P)$, dentin sialophosphoprotein (Dspp) and dentin matrix protein 1 (Dmp1). GAPDH was used as house-keeping gene to normalize RNA expression. The rat specific primers were used in the current study as described previously. ${ }^{21}$ Real-time PCR was performed using SYBR Green PCR kit (Eurogentec, Liege, Belgium) and controlled in a spectrofluorimetric thermal iCycler ${ }^{\circledR}$ (BioRad, The Netherlands). DNA amplifications were performed under the following conditions: 2 min at $50^{\circ} \mathrm{C}, 10 \mathrm{~min}$ at $95^{\circ} \mathrm{C}, 40$ cycles of $15 \mathrm{~s}$ at $95^{\circ} \mathrm{C}$ and $1 \mathrm{~min}$ at $60^{\circ} \mathrm{C}$, followed by data collection in the last $30 \mathrm{~s}$. After the real-time PCR run, the Ct-value showed how many PCR cycles were necessary to obtain a certain level of fluorescence. Amplification efficiency of different genes was determined relative to GAPDH as an internal control $\left(\Delta \mathrm{Ct}=\mathrm{Ct}_{\mathrm{gene}}-\mathrm{Ct}_{\mathrm{GAPDH}}\right)$. The mRNA in each sample was calculated by comparative $\Delta \Delta \mathrm{Ct}\left(\Delta \mathrm{Ct}_{\text {gene }}-\Delta \mathrm{Ct}_{\text {control }}\right)$ value method. ${ }^{22}$ Each sample was assessed in triplicate.

\section{In vivo analysis}

After in vitro culture for four days, 16 samples of each group ((I): F1 with cells; (II): F2 with cells; (III): F2 without cells were used for in vivo implantation. Twenty-four 10-week-old BALB/c immune-compromised nude mice were used after approval from the Radboud University Nijmegen Animal Ethics Committee (RU-DEC 2007-192). National guidelines for the care and use of laboratory animals were obeyed. Surgery was performed under general anesthesia (isoflurane 1.5-3\%). The backs of the mice were 
cleaned and disinfected with povidone-iodine. On each flank, parallel to the spinal column, one small incision of about $10 \mathrm{~mm}$ was made through the skin. Using blunt dissection, subcutaneous pockets were created. Each scaffold was folded twice into a 4-layer fan shape and inserted into the pocket. Each mouse received always two implants of different groups. After implant placement the wounds were closed using staples.

After 4 and 8 weeks of implantation, the samples were retrieved. Four samples of each group were fixed in formalin, dehydrated in a series of ethanol, and embedded in methylmethacrylate (MMA). After polymerization of the MMA, at least three thin transversal sections $(10 \mu \mathrm{m})$ of each tissue block were made using a modified sawing microtome technique. ${ }^{23}$ The sections were stained with methylene blue/basic fuchsin and analyzed using light microscopy.

The remaining four samples of each group were used for real-time PCR analysis. Fibrous tissue capsules and other surrounding tissues were removed immediately after the retrieval of the samples. The scaffolds together with the interstitial tissues were cut into small pieces and transferred to liquid nitrogen immediately. All following procedures were performed as described above and OC, BSP, Dspp and Dmpl gene expression level was determined.

\section{Statistical analysis}

Statistical significance was evaluated using one wayANOVA with post hoc Tukey testing. $p<0.05$ was considered significant. Data are represented as mean \pm standard deviation (SD).

\section{RESULTS}

\section{Characterization of nano-hydroxyapatite}

The TEM micrograph (Fig. 1) showed that the obtained particles were rod-like in shape with a length of 50-80 nm. Further, XRD was used to iden-

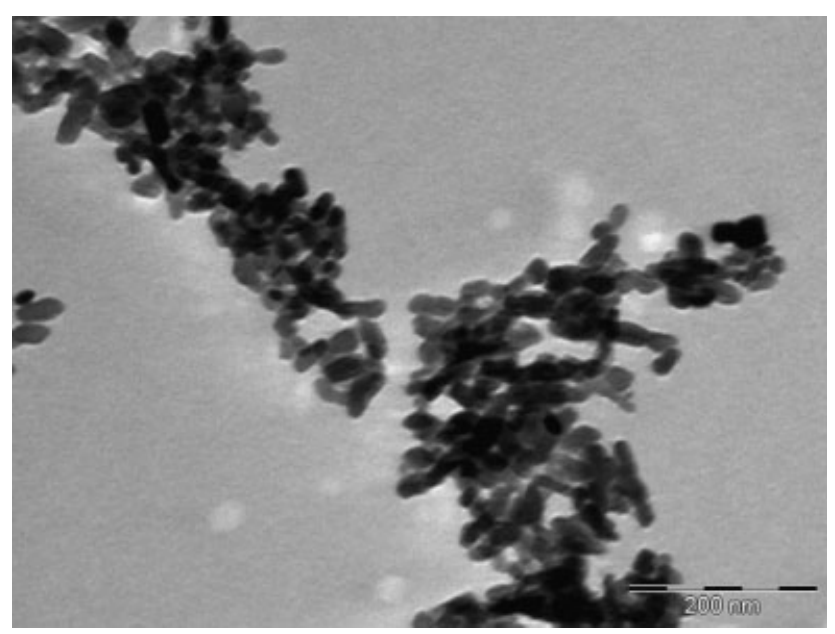

Figure 1. Transmission electron micrograph of nHA particles.
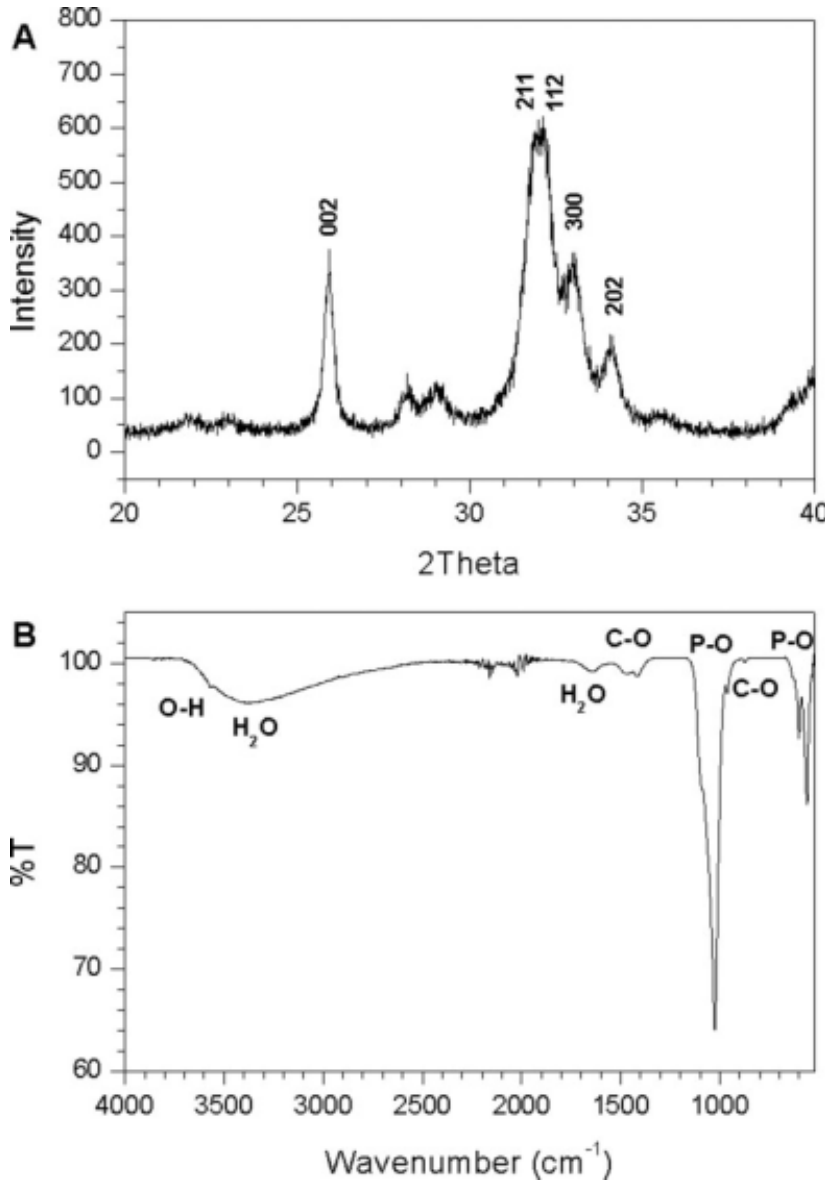

Figure 2. (A) X-ray diffraction and (B) FTIR spectra of nHA particles.

tify the crystallographic structure of the particles. The result, as shown in Figure 2(A), indicated the Bragg peaks appearing approximately at $25.9^{\circ}, 31.8^{\circ}$, $32.9^{\circ}$, and $34.1^{\circ}$ in 2-Theta corresponding to the characteristic reflections of $002,211,300$, and 202 of HA structure, respectively (JCPDS \#09-0432). Chemical functionality of the nHA was determined from the FTIR spectrum [Fig. 2(B)]. The sharp band at 3566 $\mathrm{cm}^{-1}$ represented the stretching vibration of the $\mathrm{OH}^{-1}$ ions in the HA lattice. The bands of $\mathrm{O}-\mathrm{H}$ stretching and bending were seen at 3384 and 1646 $\mathrm{cm}^{-1}$, respectively. The bands at $962\left(v_{1}\right), 1026$ and $1092\left(v_{3}\right), 563$ and $603\left(v_{4}\right) \mathrm{cm}^{-1}$ were assigned to $\mathrm{PO}_{4}^{3-}$. In addition, $\mathrm{CO}_{3}^{2-}$ was recorded by weak bands at 876,1420 and $1473 \mathrm{~cm}^{-1}$, indicating a small amount of substitution of $\mathrm{CO}_{3}^{2-}$ ions into the apatite.

\section{Characterization of scaffolds}

SEM micrographs revealed that the electrospun scaffolds were composed of randomly oriented fibers, with an average fiber diameter of $161 \mathrm{~nm}$ $(\mathrm{F} 1)$, and $281 \mathrm{~nm}(\mathrm{~F} 2)$, respectively [Fig. 3(A,B)]. In TEM observation, the surface of F2 [Fig. 3(D)] was 


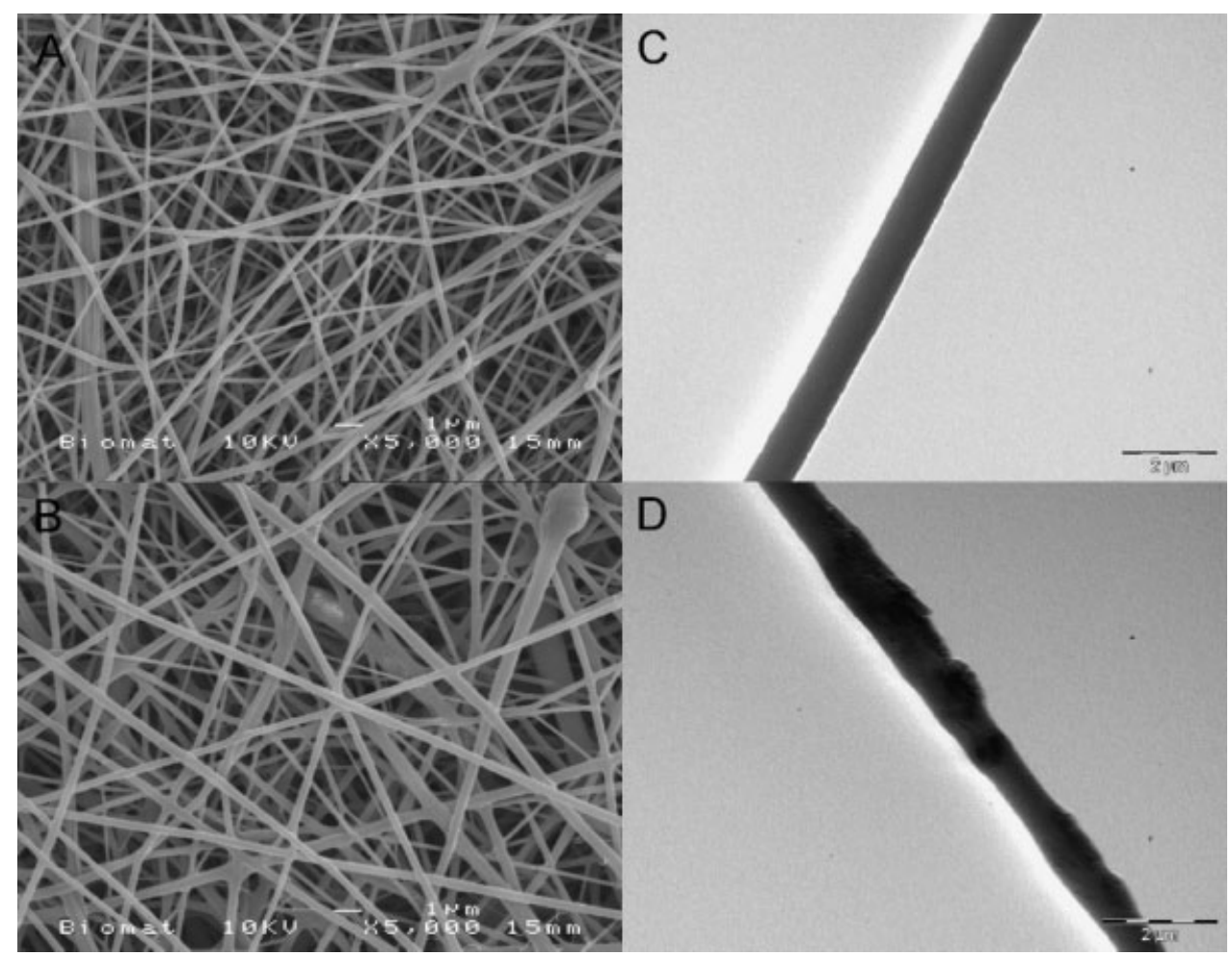

Figure 3. Scanning electron micrographs $(A, B)$ and transmission electron micrographs $(C, D)$ of the two electrospun fibrous scaffolds: (A,C) F1; (B,D) F2.

much coarser compared with that of F1 [Fig. 3(C)] because of the dispersion of nHA particles. In some regions of the fibers, the nanoparticles were well dispersed along the fiber axis, whereas in other regions they tended to aggregate. The porosity of the scaffold greatly differed in size and appearance because of the random orientation and interconnection of the fibers. In general the pore diameter ranged from several hundred nanometers to tens of micrometers.

During the water wettability test, the water drops were fully absorbed by all three types of scaffolds, indicating the hydrophilic character of all materials. However, an exact contact angle could not be assessed (i.e. apparent contact angle of $0^{\circ}$ ).

\section{Cell proliferation and ALP activity}

DNA measurement [Fig. 4(A)] for all groups showed an exponential growth until day 16, followed by a decrease. However, the F1 group had a significantly greater DNA content than the F2 (day 4,8 , and 24 ) groups. The ALP activity of rat DPSCs cultured on the different scaffold materials is depicted in Figure 4(B). The ALP activity gradually increased from day 1 and reached a peak value on day 16. The cells cultured on scaffold F2 showed significantly higher levels on day 8 and 16, compared to F1.

\section{Osteocalcin deposition}

The deposition of osteocalcin was measured on days 16 and 24 after cell seeding. No significant differences in osteocalcin were observed between F1 $(8.42 \pm 1.98 \mathrm{ng} / \mathrm{mL})$ and F2 $(9.46 \pm 1.32 \mathrm{ng} / \mathrm{mL})$ on day 16. However, compared with F1 $(14.36 \pm 2.14$ $\mathrm{ng} / \mathrm{mL}$ ), a significantly higher level was observed for F2 $(22.14 \pm 4.54 \mathrm{ng} / \mathrm{mL})$ on day $24(p<0.01)$.

\section{Cell morphology}

Upon visual inspection the fibrous morphology of all the scaffolds retained unaltered for the 16-day culturing period. One day postseeding, cells adhered well and gradually spread similarly on the surfaces of both scaffolds [Fig. 5(A,B)], and showed obvious proliferation towards day 4 [Fig. $5(\mathrm{D}, \mathrm{E})]$. On day 16 , a noticeable amount of mineralized globular accretions was observed on the cell-scaffold complexes [Fig. 5(G,H)]. The blank F2 scaffolds without cells did not demonstrate obvious morphological changes or spontaneous mineralization during the 16 days of incubation [Fig. 5(C,F,I)]. The mineral nature of the deposits was confirmed by energy dispersive X-ray spectroscopy (EDS) analysis, which revealed the presence of calcium and phosphorous deposit at a Ca:P ratio of 1.5-1.6. 

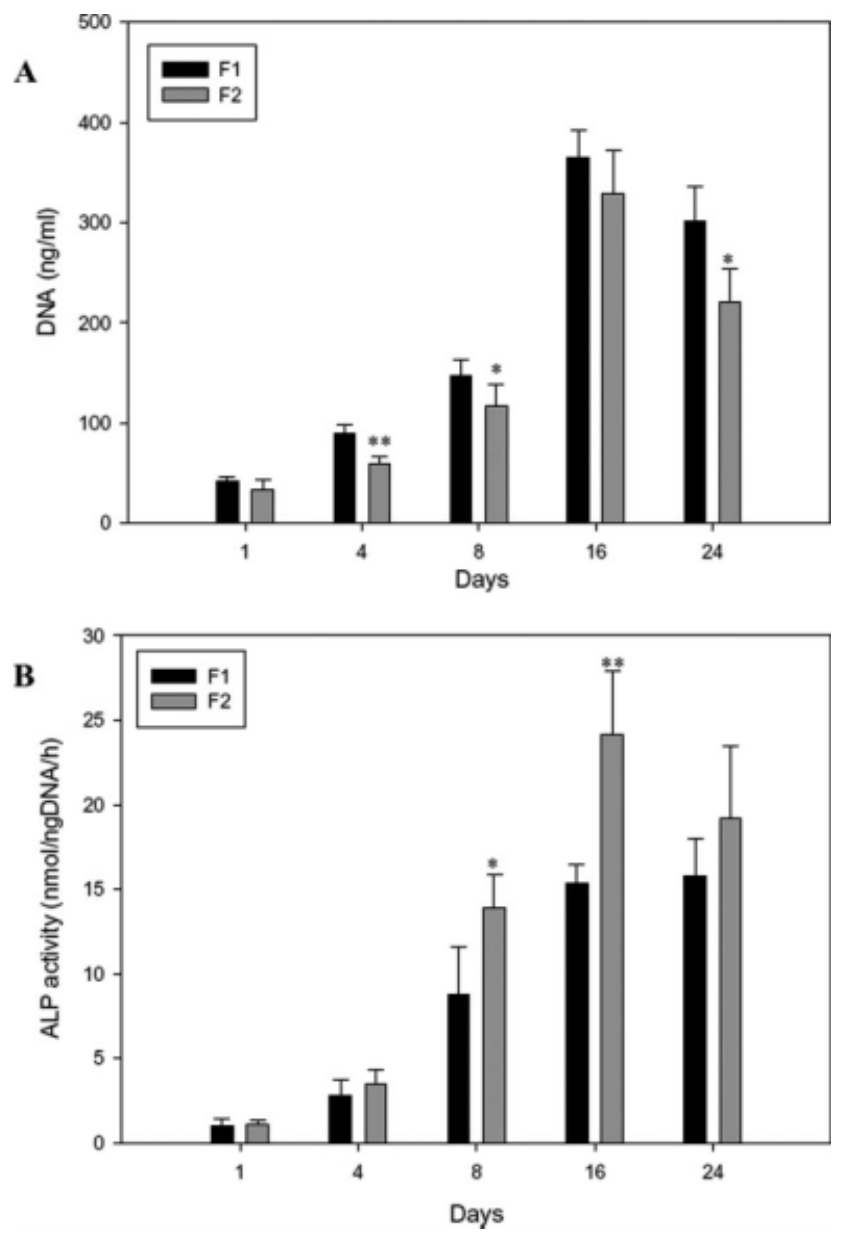

Figure 4. Growth characteristics of in vitro cultured cells: (A) total DNA content and (B) ALP activity. The bars represent the mean $\pm \mathrm{SD}(n=3)$. F2 compared to F1 group: ${ }^{*} p<0.05,{ }^{* *} p<0.01$.

\section{Real-time PCR}

Expression levels of mRNA for OC, BSP, Dspp and Dmp1 were compared on day 4, 8, and 16. The mRNA expression level of cells from F1 scaffolds at day 1 of incubation was set as baseline control with a relative expression value of $100 \%$. The expression levels of $O C$ and $B S P$ showed obvious upregulation post 8 days of incubation on all materials, and F2 scaffolds showed a significantly higher level compared to the F1 scaffold [Fig. 6(A,B)]. The mRNA expression of Dspp was significantly higher for cells on F2 scaffolds at 8 days of incubation. At 16 days of incubation, expression increased abruptly for both materials, but the F2 scaffold showed a significantly higher level compared to F1 [Fig. 6(C)]. Finally, the expression of Dmp1 increased over time, and at 8 and 16 days of incubation the F2 scaffolds obviously had higher levels compared to F1 scaffolds [Fig. 6(D)].

\section{In vivo analysis}

All mice appeared to be in good health throughout the test period. There were no symptoms of severe inflammation at the implantation sites. After sacrifice, all implants were retrieved with the surrounding soft tissues intact.

\section{Light microscopic evaluation}

Histological observation indicated that all experimental and control electrospun nanofiber implants were surrounded by a thin fibrous tissue capsule of 4-6 layers of fibroblasts in thickness, closely following the outer perimeter of the scaffold. Inflammatory cells were only sporadically present. As all the scaffolds have been folded twice before implantation, the four-layer structure can be observed as well. Further, there was no sign of tissue ingrowth or infiltration for all of the implanted scaffolds. Also, it was noted that the F2 scaffolds were partially stained red [Fig. 7(H,I)], but it can be easily distinguished from the newly formed bone-like hard tissue which was also stained red with blue cell nuclei inside.

In detail, after the 4-week implantation time, both F1 and F2 composite nanofibrous implants seeded with DPSCs intermittently indicated hard tissue formation. The newly formed hard tissue was resided mainly on the surface of the lamellae of materials [Fig. 7(A,B)]. After 8 weeks of implantation, both groups showed more hard tissue formation compared to the 4-week group [Fig. 7(D,E)]. On the other hand, no evident hard tissue formation occurred in the implants of F2 scaffold material without cell seeding during the 8-week implantation period [Fig. 7(C,F)].

At higher magnification, no significant differences was discovered between F1 and F2 with cells of both implantation periods. Distinct new bone-like hard tissues were observed with entrapped osteocyte-like cells and osteoblast-like cells lying orderly arranged at the surface [Fig. $7(\mathrm{G}, \mathrm{H})$ ]. For the control group (F2 without cells), only an orderly arranged thick fibrillike extracellular matrix (ECM) was seen along the surface of materials after 8 weeks of implantation [Fig. 7(I)].

\section{Real-time PCR}

In the real-time PCR analysis (Fig. 8), the mRNA expression levels of DPSCs seeded on F1 before implantation (day 4) were set as baseline control (relative expression value, $100 \%$ ). The mRNA levels for OC, Bsp, Dspp, and Dmp1 expression increased during implantation time form both cell-seeded F1 and 


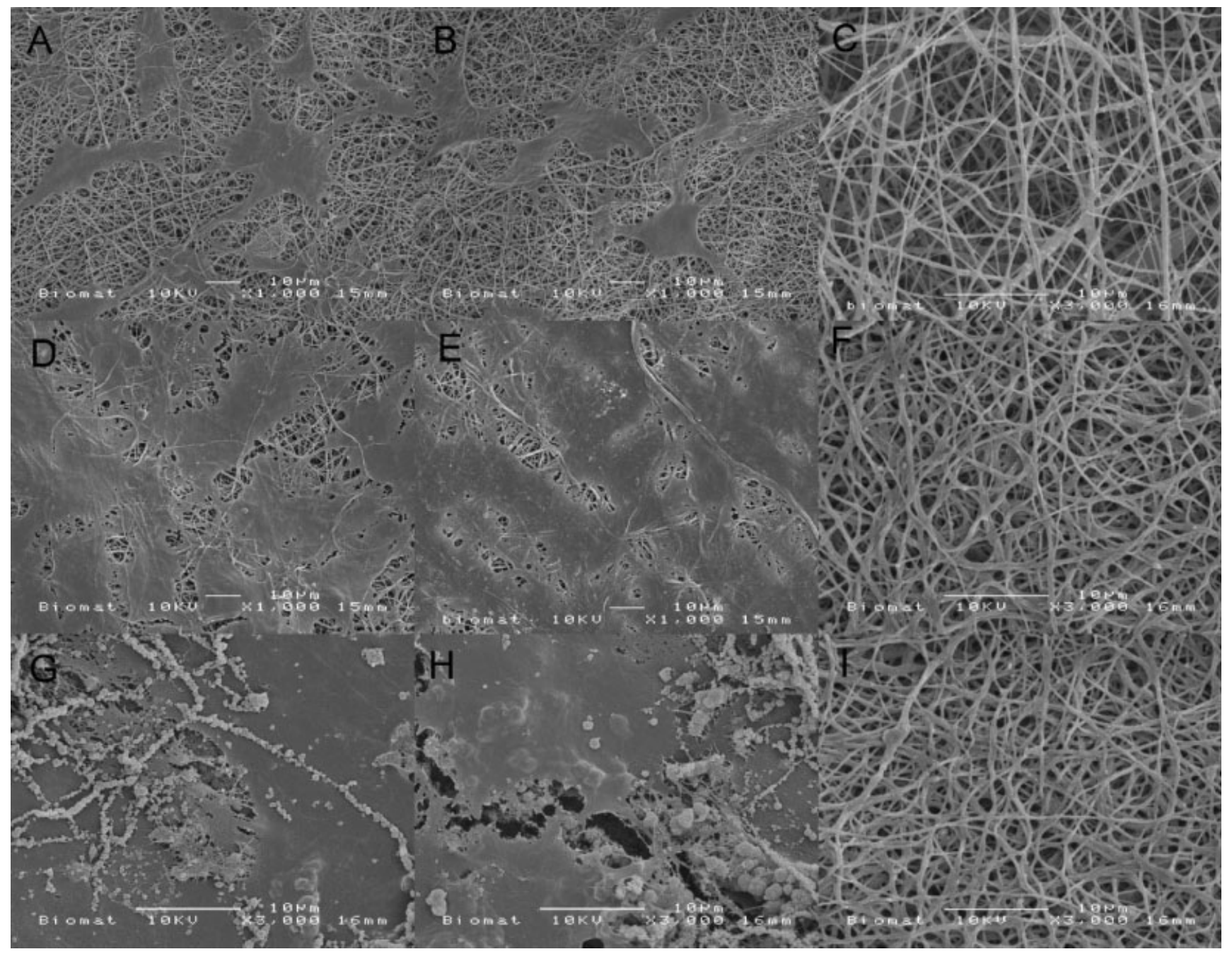

Figure 5. Scanning electron micrographs of DPSCs cultured on different groups of scaffolds: (A) F1, (B) F2, (C) control (F2 without cells) for day 1; (D) F1, (E) F2, (F) control for on day 4; (G) F1, (H) F2, (I) control for day 16. The magnification is $\times 1000$ for $\mathrm{A}, \mathrm{B}, \mathrm{D}$ and $\mathrm{E}$, and $\times 3000$ for $\mathrm{C}, \mathrm{F}-\mathrm{I}$.

F2 scaffolds. Further, both groups revealed a similar expression profile for these genes. However, the cell-seeded F2 scaffolds indicated significant upregulation of expression of all four measured genes compared to the cell-seeded F1 scaffolds for both implantation periods. As for the control group (F2 without cells), no expression of these four genes was found during the whole 8-week implantation.

\section{DISCUSSION}

In this study, two kinds of composite fibrous scaffolds were successfully spun (F1 and F2), which all had fiber diameters of less than $500 \mathrm{~nm}$. The average diameter of F1 was smaller compared to F2, indicating that the addition of nHA augments the fiber size. The concentration of nHA used in this study was based on the literature, and chosen in such a way to avoid agglomeration of the nanoparticles. ${ }^{24,25}$ However, some heterogeneity of nHA distribution in the electrospun fibers could still be observed under SEM. In future studies, the addition of a surfactant should be considered to avoid this problem. ${ }^{26}$

Subsequently, rat DPSCs were seeded on the electrospun nanocomposite scaffolds. The SEM micrographs showed that cells attached and spread well on the surfaces of both scaffolds from day 1 post seeding. Such a response indicates good cyto-compatibility and close interaction of the nanofibers with rat DPSCs. Previous investigations also showed favorable cell-scaffold interactions on electrospun scaffolds for bone cells, fibroblasts, neural cells and smooth muscle cells. ${ }^{27}$ This may be due to morphological advantages of electrospun scaffolds, for example, the ultrafine fiber size comparable to natural ECM and combined with a high specific surface 

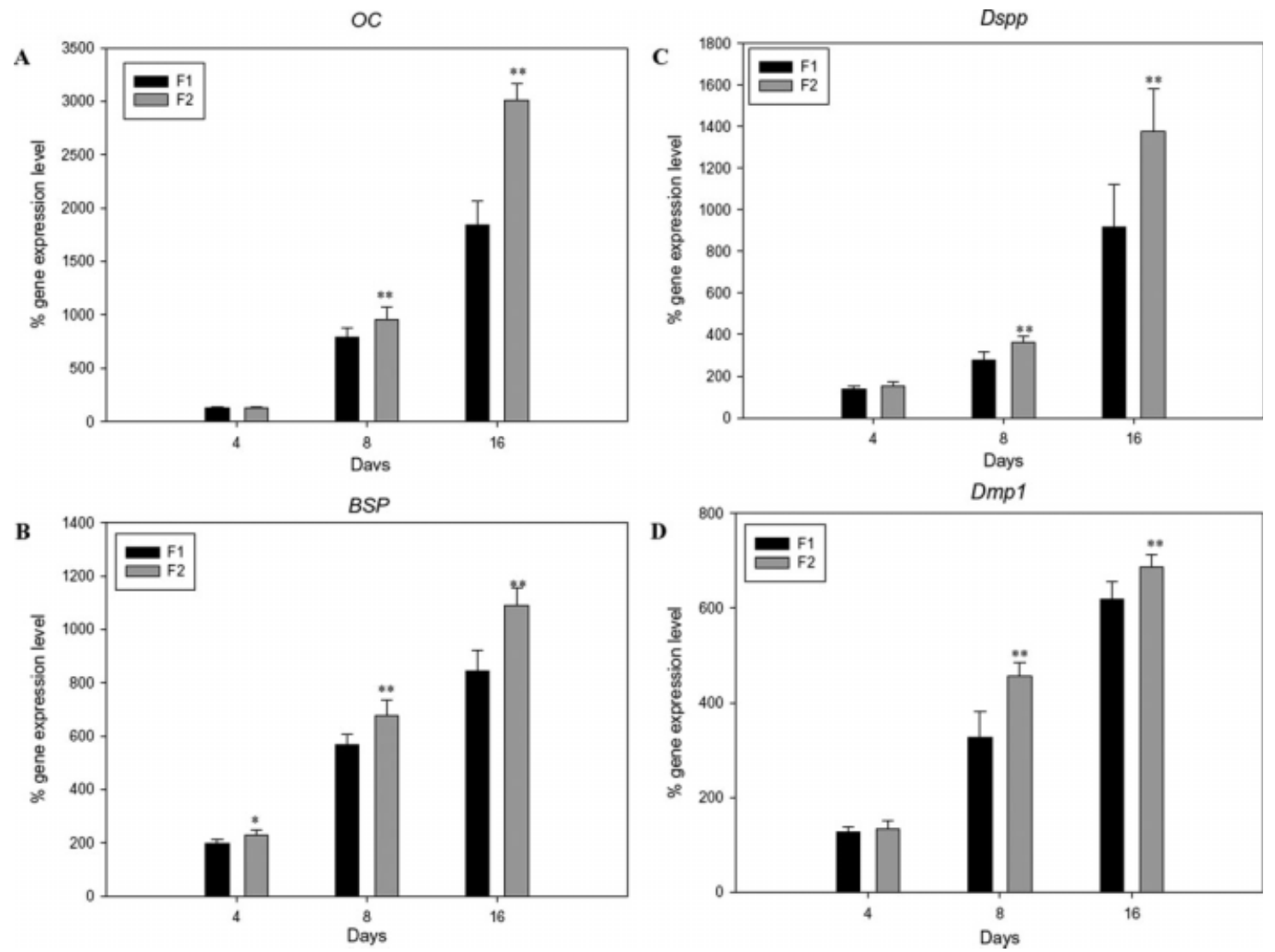

Figure 6. In vitro measurement of the mRNA levels of OC (A); BSP (B); Dspp (C); Dmp1 (D). The bars represent the mean $\pm \mathrm{SD}(n=3)$. F2 compared to F1 group: ${ }^{*} p<0.05,{ }^{* *} p<0.01$; the comparison within each group between different time always shows $p<0.01$ (not marked in figures).

area and porosity. Analogous with the cell types mentioned, DPSCs are anchorage-dependent cells, and thus the unique morphology of electrospun scaffolds may also aid DPSC attachment and migration.

Further, the effect of adding nHA to the electrospun scaffold was studied. The results from the DNA assay showed that the addition of $\mathrm{nHA}$ did not present an advantage for cell attachment and growth, which is in contrast with a previous study of Kim et al., who showed that electrospun nanocomposite fibers of $\mathrm{HA} /$ poly(lactic acid) (PLA) enhanced cell adhesion and proliferation compared to the pure polymer material. ${ }^{17}$ An explanation might be that PLA is hydrophobic, and the subsequent blending of HA powder improves the hydrophilicity of the PLA resulting in enhanced cell adhesion and proliferation. ${ }^{17}$ The currently used composite of PCL and gelatin already possesses hydrophilic properties as indicated by the water wettability test, which is not further increased by the addition of HA.

Among the analyzed phenotype markers, ALP is regarded as an early marker of osteo/odontogenic differentiation and expressed during the postproliferative period of extracellular-matrix maturation, indicating the potential of hard tissue formation. OC is a noncollagenous protein present in both dentin and bone matrix and expression occurs later during the final period of ECM mineralization. ${ }^{28}$ The ALP data revealed that both scaffolds supported the differentiation of DPSCs and also indicated that the addition of nHA (F2) can promote this differentiation process compared to pure PCL/gelatin material (F1). These results corroborate with a previous study on the behavior of bone cells. ${ }^{17}$ Although the underlying mechanism for this phenomenon is not clear, a hypothesis is that the inclusion of bioactive HA results in dissolution and precipitation of calcium and phosphate ions out of the fiber surface layer, resulting in the formation of a microenvironment that resembles the natural pulp and stimulates odontogenic differentiation. ${ }^{29}$ It is known that the size, morphology and structure of HA all influence the biological response, and thus it seems possible that nano-sized HA with a high solubility will have a marked influence on the bioactivity. ${ }^{18,30}$ The effect of the composite with nHA on DPSCs differentiation was also evidenced by the increased deposition of OC in the ECM. This corroborates other studies that have demonstrated the cytoactive nature of HA. ${ }^{31,32}$ 


\section{F1 with cells}

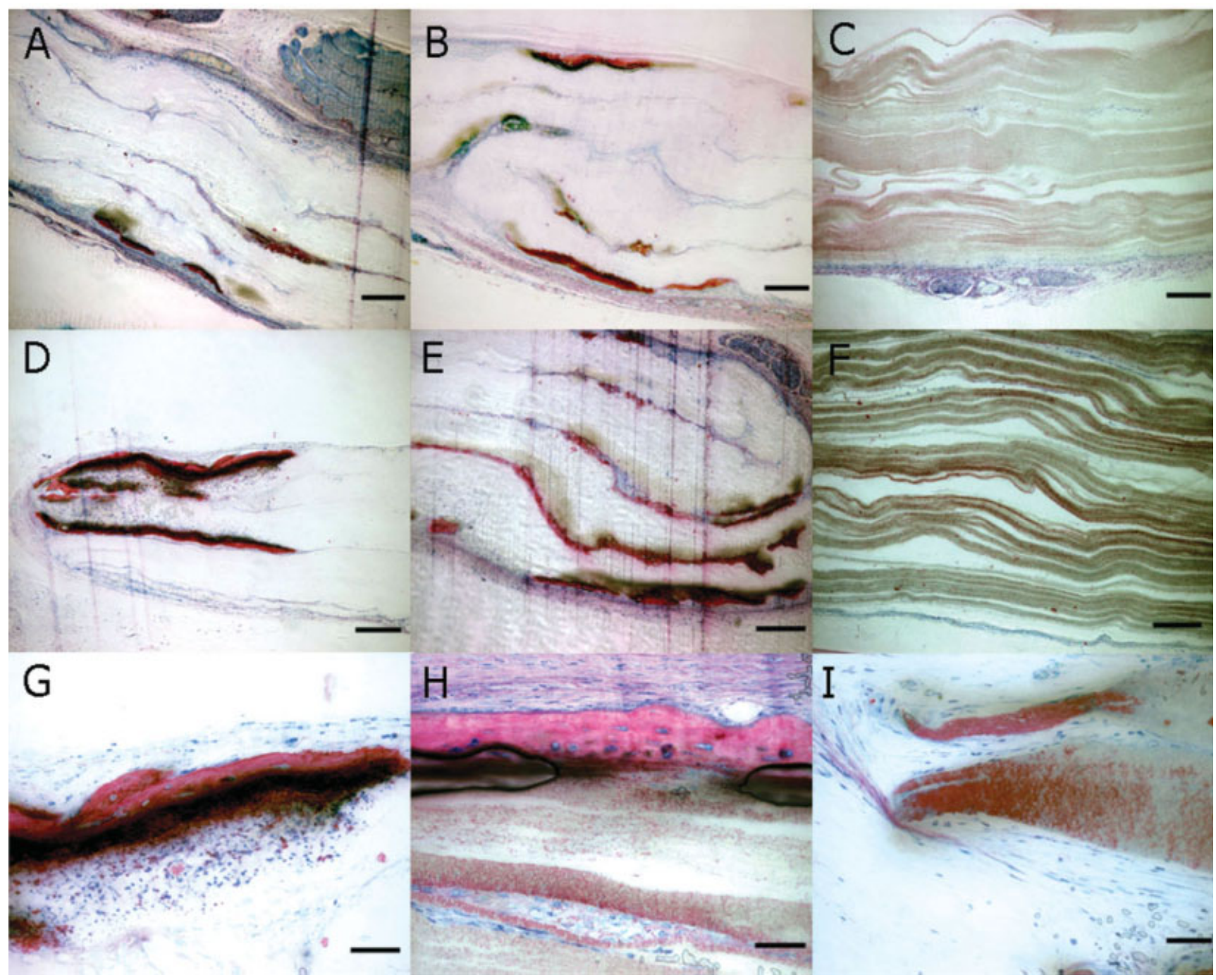

Figure 7. Histology of implanted scaffolds. (A-F) General overview of the implants of 4 and 8 weeks (methylene blue basic/fuchsin staining); Scale bar is $100 \mu \mathrm{m}$ (original magnification $\times 10$ ). (G-I) Histology and morphology of implants of 8 weeks at a high magnification (original magnification $\times 40$ ), bar size is $25 \mu \mathrm{m}$ : $\mathrm{G}$ and $\mathrm{H}$ showed the presence of bone-like matrix with entrapped osteocyte-like cells and osteoblast-like cells lying orderly arranged at the surface; I showed an orderly arranged thick fibril-like extracellular matrix (ECM) along the surface of the scaffold. [Color figure can be viewed in the online issue, which is available at www.interscience.wiley.com.]

The mRNA expression levels of OC, BSP, DSPP, and $D M P-1$ were chosen as markers for the odontogenic phenotype. Analogous to OC, BSP is regarded a late marker for osteoblast differentiation and plays an important role in hard tissue regeneration. ${ }^{28}$ Dspp is the major noncollagenous protein in dentin and plays a crucial role during dentin mineralization. ${ }^{33-35}$ Dmp1 is another specific protein in dentin, and is a candidate gene for dentinogenesis imperfecta. ${ }^{36}$ It was observed that the mRNA expression profiles of both groups in our study showed similar profiles. Moreover, important differences occurred from day 4 to 16 . The expression of $O C$, $B S P, D s p p$ and Dmp1 was most effectively enhanced by the addition of nHA to the fibers (F2), compared to the F1 group. In the current study, the RT-PCR data matches the protein expression data fairly well. However, the expression of mRNA is always prior to protein expression. The expression of the markers offers strong evidence that: (1) DPSCs differentiate towards odontoblast phenotype, and (2) the addition of $\mathrm{nHA}$ indeed promotes this differentiation efficacy.

In the in vivo part of our study, the implants showed abundant soft tissue reaction without evoking a severe inflammatory response, which evidenced the biocompatibility of the used electrospun materials. Still, newly formed bone-like hard tissue was found only in limited quantity in the electro- 


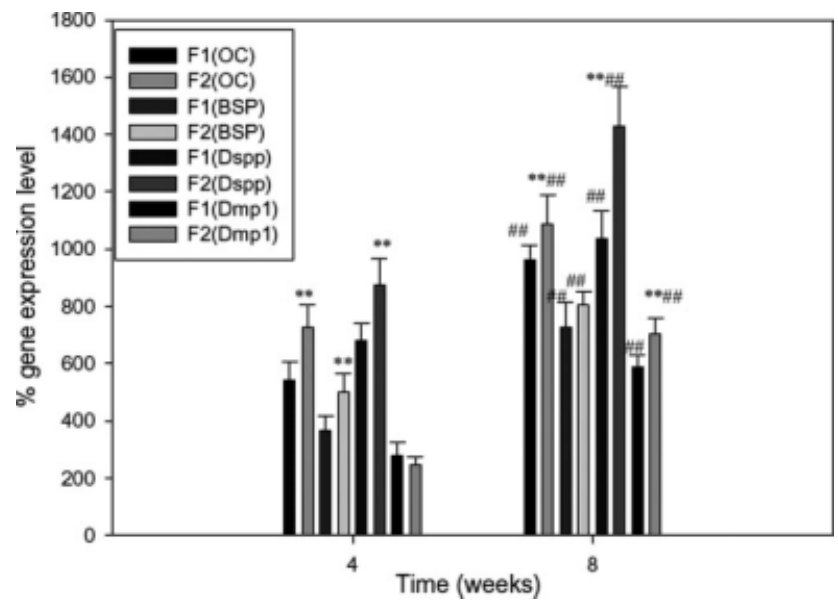

Figure 8. In vivo expression of the mRNA levels of $O C$, $B S P, D s p p$, and Dmp1; quantified for the in vivo specimens. The bars represent the mean $\pm \mathrm{SD}(n=3)$. F2 compared to F1: ${ }^{*} p<0.05,{ }^{* *} p<0.01$; Comparison between week 8 and week 4 within same groups: ${ }_{p}^{p}<0.05,{ }^{\# \#} p<0.01$.

spun implants loaded with DPSCs when compared to our previous study. ${ }^{37}$ The divergent in vivo results can be attributed to the small pore size of the electrospun fibrous scaffolds, which limited the space for new tissue formation and ingrowth. A previous study claimed that a similar gelatin/PCL electrospun fibrous structure allowed a cellular penetration or infiltration into the scaffold, but it was evidenced by confocal microscopy in a in vitro cell culture system. ${ }^{12}$ An uneven surface might cause the artifacts. Furthermore, a typical dentin-pulp-like structure could not be observed on the scaffolds, even though Dspp and Dmp1 were present as observed by the real-time PCR, which is in line with the results of the previous studies. ${ }^{37,38}$

This study demonstrates that the addition of nHA in the electrospun scaffolds has positive effect on the differentiation of DPSCs. One of the potential clinical applications of this DPSC loaded electrospun scaffold may be the regeneration of the dentin-pulp complex via dental pulp capping procedure. ${ }^{39}$ The current pulp capping materials, such as calcium hydroxide and calcium phosphate cement, are not able to really induce new tissue formation, neither chemically stable for cell loading. ${ }^{40,41}$ The flexibility of electrospun scaffolds facilitate the application of DPSCs in the pulp cavities in order to help new tooth tissue generation. ${ }^{39}$ However, to actually progress to potential therapeutic application towards dentin regeneration, improved scaffold designs in composition as well as morphology are essential. Especially, the appropriate pore structure and nHA content of materials should be further tailored to augment the efficacy of hard tissue formation.

\section{CONCLUSION}

In conclusion, the results of present study showed that electrospun composite scaffolds made of PCL/ gelatin/nHA and PCL/gelatin, supported the proliferation and odontogenic differentiation of DPSCs. Furthermore, the data indicated that both in vitro and in vivo odontogenic differentiation of the seeded rat DPSCs can significantly increased by the addition of nHA. However, it has to be emphasized that the small pore size of the electrospun scaffolds hindered tissue ingrowth. Control PCL/gelatin/nHA scaffolds without cells did not support bone-like tissue formation in vivo.

The authors thank Lise de Jonge for her technical assistance. SEM was performed at the Microscopic Imaging Centre (MIC) of the Nijmegen Centre for Molecular Life Sciences (NCMLS), The Netherlands.

\section{References}

1. Zhang W, Walboomers XF, Wolke JGC, Bian Z, Fan MW, Jansen JA. Differentiation ability of rat postnatal dental pulp cells in vitro. Tissue Eng 2005;11:357-368.

2. Yu J, Deng Z, Shi J, Zhai H, Nie X, Zhuang H, Li Y, Jin Y. Differentiation of dental pulp stem cells into regular-shaped dentin-pulp complex induced by tooth germ cell conditioned medium. Tissue Eng 2006;12:3097-3105.

3. Langer R, Vacanti JP. Tissue engineering. Science 1993;260: 920-926.

4. Pham QP, Sharma U, Mikos AG. Electrospinning of polymeric nanofibers for tissue engineering applications: A review. Tissue Eng 2006;12:1197-1211.

5. Li WJ, Laurencin CT, Caterson EJ, Tuan RS, Ko FK. Electrospun nanofibrous structure: A novel scaffold for tissue engineering. J Biomed Mater Res 2002;60:613-621.

6. Yoshimoto H, Shin YM, Terai H, Vacanti JP. A biodegradable nanofiber scaffold by electrospinning and its potential for bone tissue engineering. Biomaterials 2003;24:2077-2082.

7. Shin M, Yoshimoto H, Vacanti JP. In vivo bone tissue engineering using mesenchymal stem cells on a novel electrospun nanofibrous scaffold. Tissue Eng 2004;10:33-41.

8. Chong EJ, Phan TT, Lim IJ, Zhang YZ, Bay BH, Ramakrishna $\mathrm{S}$, Lim CT. Evaluation of electrospun PCL/gelatin nanofibrous scaffold for wound healing and layered dermal reconstitution. Acta Biomater 2007;3:321-330.

9. Li WJ, Danielson KG, Alexander PG, Tuan RS. Biological response of chondrocytes cultured in three-dimensional nanofibrous poly(epsilon-caprolactone) scaffolds. J Biomed Mater Res A 2003;67:1105-1114.

10. Xu CY, Inai R, Kotaki M, Ramakrishna S. Electrospun nanofiber fabrication as synthetic extracellular matrix and its potential for vascular tissue engineering. Tissue Eng 2004;10: 1160-1168.

11. Yang F, Murugan R, Wang S, Ramakrishna S. Electrospinning of nano/micro scale poly(L-lactic acid) aligned fibers and their potential in neural tissue engineering. Biomaterials 2005;26:2603-2610.

12. Zhang YZ, Ouyang HW, Lim CT, Ramakrishna S, Huang $\mathrm{ZM}$. Electrospinning of gelatin fibers and gelatin/PCL composite fibrous scaffolds. J Biomed Mater Res B 2005;72: 156-165. 
13. Hayashi $\mathrm{Y}$, Imai M, Yanagiguchi $\mathrm{K}$, Viloria IL, Ikeda T. Hydroxyapatite applied as direct pulp capping medicine substitutes for osteodentin. J Endod 1999;25:225-229.

14. Webster TJ, Ergun C, Doremus RH, Siegel RW, Bizios R. Enhanced osteoclast-like cell functions on nanophase ceramics. Biomaterials 2001;22:1327-1333.

15. Balasundaram G, Sato M, Webster TJ. Using hydroxyapatite nanoparticles and decreased crystallinity to promote osteoblast adhesion similar to functionalizing with RGD. Biomaterials 2006;27:2798-2805.

16. Sui G, Yang X, Mei F, Hu X, Chen G, Deng X, Ryu S. PolyL-lactic acid/hydroxyapatite hybrid membrane for bone tissue regeneration. J Biomed Mater Res A 2007;82:445-454.

17. Kim HW, Lee HH, Knowles JC. Electrospinning biomedical nanocomposite fibers of hydroxyapaite/poly(lactic acid) for bone regeneration. J Biomed Mater Res A 2006;79:643-649.

18. Huang J, Lin YW, Fu XW, Best SM, Brooks RA, Rushton N, Bonfield W. Development of nano-sized hydroxyapatite reinforced composites for tissue engineering scaffolds. J Mater Sci Mater Med 2007;18:2151-2157.

19. Inoue $M$, LeGeros $R Z$, Inoue $M$, Tsujigiwa $H$, Nagatsuka $H$, Yamamoto T, Nagai N. In vitro response of osteoblast-like and odontoblast-like cells to unsubstituted and substituted apatites. J Biomed Mater Res A 2004;70:585-593.

20. Yang F, Wolke JGC, Jansen JA. Biomimetic calcium phosphate coating on electrospun poly(e-caprolactone) scaffolds for bone tissue engineering. Chem Eng J 2008;137:154-161.

21. Yang X, van den DJ, Walboomers XF, Zhang W, Bian Z, Fan $\mathrm{M}$, Jansen JA. The odontogenic potential of STRO-1 sorted rat dental pulp stem cells in vitro. J Tissue Eng Regen Med 2007;1:66-73.

22. Livak KJ, Schmittgen TD. Analysis of relative gene expression data using real-time quantitative PCR and the $2^{-\Delta \Delta C T}$ method. Methods 2001;25:402-408.

23. van der Lubbe HB, Klein CP, de Groot K. A simple method for preparing thin (10 microM) histological sections of undecalcified plastic embedded bone with implants. Stain Technol 1988;63:171-176.

24. Catledge SA, Clem WC, Shrikishen N, Chowdhury S, Stanishevsky AV, Koopman M, Vohra YK. An electrospun triphasic nanofibrous scaffold for bone tissue engineering. Biomed Mater 2007;2:142-150.

25. Thomas V, Jagani S, Johnson K, Jose MV, Dean DR, Vohra YK, Nyairo E. Electrospun bioactive nanocomposite scaffolds of polycaprolactone and nanohydroxyapatite for bone tissue engineering. J Nanosci Nanotechnol 2006;6:487-493.

26. Kim HW. Biomedical nanocomposites of hydroxyapatite/polycaprolactone obtained by surfactant mediation. J Biomed Mater Res A 2007;83:169-177.

27. Zhang YZ, Lim CT, Ramakrishna S, Huang ZM. Recent development of polymer nanofibers for biomedical and biotechnological applications. J Mater Sci Mater Med 2005;16:933-946.
28. Dragoo JL, Choi JY, Lieberman JR, Huang J, Zuk PA, Zhang J, Hedrick MH, Benhaim P. Bone induction by BMP-2 transduced stem cells derived from human fat. J Orthop Res 2003;21:622-629.

29. Tabata S, Nakayama T, Funakoshi K, Yasui K, Wada K, Uemura M. Collagen fibrils in the odontoblast layer of the rat incisor by scanning electron-microscopy using the maceration method. Anat Rec 1994;239:360-370.

30. Guo XY, Gough JE, Xiao P, Liu J, Shen ZJ. Fabrication of nanostructured hydroxyapatite and analysis of human osteoblastic cellular response. J Biomed Mater Res A 2007;82: 1022-1032.

31. van der Wal E, Wolke JGC, Jansen JA, Vredenberg AM. Initial reactivity of $\mathrm{rf}$ magnetron sputtered calcium phosphate thin films in simulated body fluids. Appl Surf Sci 2005;246: 183-192.

32. Shu R, McMullen R, Baumann MJ, Mccabe LR. Hydroxyapatite accelerates differentiation and suppresses growth of MC3T3-E1 osteoblasts. J Biomed Mater Res A 2003;67: 1196-1204.

33. Kim JW, Nam SH, Jang KT, Lee SH, Kim CC, Hahn SH, Hu JCC, Simmer JP. A novel splice acceptor mutation in the DSPP gene causing dentinogenesis imperfecta type II. Hum Genet 2004;115:248-254.

34. Butler WT. Dentin matrix proteins. Eur J Oral Sci 1998;106:204-210.

35. Feng JQ, Luan XH, Wallace J, Jing D, Ohshima T, Kulkarni AB, D'Souza RN, Kozak CA, Macdougall M. Genomic organization, chromosomal mapping, and promoter analysis of the mouse dentin sialophosphoprotein (Dspp) gene, which codes for both dentin sialoprotein and dentin phosphoprotein. J Biol Chem 1998;273:9457-9464.

36. Macdougall M, Gu TT, Simmons D. Dentin matrix protein-1, a candidate gene for dentinogenesis imperfecta. Connect Tissue Res 1996;35:267-272.

37. Yang X, Walboomers XF, van den Beucken JJ, Bian Z, Fan M, Jansen JA. Hard tissue formation of STRO-1-selected rat dental pulp stem cells in vivo. Tissue Eng Part A. Forthcoming.

38. Zhang WB, Walboomers $\mathrm{XF}$, van Kuppevelt $\mathrm{TH}$, Daamen WF, Bian Z, Jansen JA. The performance of human dental pulp stem cells on different three-dimensional scaffold materials. Biomaterials 2006;27:5658-5668.

39. Zhang W, Walboomers XF, Jansen JA. The formation of tertiary dentin after pulp capping with a calcium phosphate cement, loaded with PLGA microparticles containing TGF- $\beta 1$. J Biomed Mater Res A 2008;85:439-444.

40. Olsson H, Petersson K, Rohlin M. Formation of a hard tissue barrier after pulp cappings in humans. A systematic review. Int Endod J 2006;39:429-442.

41. Link DP, van den Dolder J, Wolke JGC, Jansen JA. The cytocompatibility and early osteogenic characteristics of an injectable calcium phosphate cement. Tissue Eng 2007;13:493-500. 